\title{
Uma contribuição da metodologia Peir para o estudo de uma pequena cidade na Amazônia: Ponta de Pedras, Pará'
}

\section{A contribution from the DPSIR methodology to the study of a small town in the Amazon: Ponta de Pedras, Pará, Brazil}

\author{
Viviana Mendes Lima \\ Universidade de São Paulo. Faculdade de Saúde Pública. \\ Departamento Saúde Ambiental. São Paulo, SP, Brasil. \\ E-mail: geomendesळusp.br

\section{Sandra Maria Fonseca da Costa} \\ Universidade do Vale do Paraíba. Planejamento Urbano e \\ Regional. Laboratório de Estudo das Cidades. São José dos \\ Campos, SP, Brasil. \\ E-mail: sandraœunivap.br

\section{Helena Ribeiro} \\ Universidade de São Paulo. Faculdade de Saúde Pública. \\ Departamento Saúde Ambiental. São Paulo, SP, Brasil. \\ E-mail: lenaœusp.br
}

\section{Correspondência}

Viviana Mendes Lima

Laboratório de Estudos das Cidades. Rua Shishima Hifumi, 29ı. São

José dos Campos, SP, Brasil. CEP 12244-000.

\section{Resumo}

Este artigo objetivou analisar a contribuição da metodologia Peir para estudo de uma pequena cidade da Amazônia a partir da análise do modo de vida da população. Como procedimento metodológico procurou-se entender a relação entre aspectos de urbanização conectados à globalização e saúde da população dessa cidade. Foram obtidos dados em campo, os quais permitiram analisar a situação de saúde em dois setores urbanos. A metodologia Pressão-Estado-Impacto-Resposta (Peir), desenvolvida pelo Programa das Nações Unidas para o Meio Ambiente (Pnuma) e adaptada pela Organização para a Cooperação e Desenvolvimento Econômico (OCDE), servirá de suporte para a compreensão dos impactos na saúde da população a partir do acesso a infraestruturas disponíveis, entre elas o abastecimento de água. O local de estudo é cidade de Ponta de Pedras, situada na Ilha do Marajó, estado do Pará, Brasil. Como resultado nota-se a necessidade de intervenções imediatas por parte do poder público para minimizar os impactos das condições de vulnerabilidade sobre as populações.

Palavras-chave: Cidades Pequenas; Saúde; Ambiente; Peir.

1 Pesquisa financiada pela Coordenação de Aperfeiçoamento de Pessoal de Nível Superior (Capes) e pela Fundação de Amparo à Pesquisa do Estado de São Paulo (Fapesp). 
Abstract

This article aimed to analyze DPSIR approach's contribution in an Amazonian small town, according to the local people's lives. As methodological procedure, we sought to understand the relation between urbanization aspects connected to globalization and the population health of said small town. For this research, data were obtained in field, which allowed an analysis of the health situation in two urban sectors. The DPSIR methodology - Driving force-PressureState-Impact-Response, developed by United Nations Environment (UNE) and adapted by the Organization for Economic Cooperation and Development (OECD), will serve as support for the understanding of impacts on the population's health, analyzing issues as access to available infrastructure, including water supply. As a result, Ponta de Pedras town, located in Marajó Island (PA), Brazil - where the research was performed -, requires an immediate intervention from the public authorities to minimize impacts of population's exposure to vulnerable conditions.

Keywords: Small Towns; Health; Environment; DPSIR.

\section{Introdução}

A globalização, entendida como fase de internacionalização do capitalismo, é também o símbolo da vida moderna diante das modificações econômicas e sociais que se estabelecem a partir de um modelo de desenvolvimento. Essas modificações foram iniciadas durante a revolução tecnológica que transformou o modo de produção, assim como as relações de trabalho, em mercadorias facilmente negociáveis, o que se refletiu na organização do espaço urbano. Nesse sentido, Corrêa (1999, p. 44) analisa que:

a globalização causa vigoroso impacto sobre as esferas econômicas, social, política e cultural, mas também, e simultaneamente sobre a organização espacial que tanto reflete como condiciona aquelas esferas. [...] Trata-se de uma reestruturação espacial que se manifesta, no plano mais geral, na recriação das diferenças entre regiões e centros urbanos, assim como nas articulações entre ambos e entre os centros.

Bauman (1999, p. 8) explica que "ser local num mundo globalizado é sinal de privação e degradação social”. O autor avalia que as transformações advindas da globalização trouxeram novos modelos de desenvolvimento, e uma nova sociedade se consolidou em países desenvolvidos com os avanços da tecnologia a partir da industrialização.

Essa internacionalização da economia trouxe problemas que emergiram em alguns setores da sociedade, como meio ambiente e saúde. Em determinados casos esses problemas se associam a parâmetros qualitativos, por exemplo, a perda da paisagem, a partir da degradação ambiental. Os impactos à saúde são diversos, em especial quando relacionados às condições de renda, acesso à educação, infraestrutura, alimentação e expectativa de vida.

A partir da internacionalização da economia e do processo de globalização problemas e preocupações maiores vinculadas à saúde emergiram. Recentes doenças globais transmitidas por fronteiras aéreas ou terrestres, como a Sars na Ásia, o ebola e a febre hemorrágica na África, são exemplos de ações urgentes em políticas globais para prevenção e diagnóstico cada vez mais precoces na atenção em saúde, a fim de evitar que os países de economia periférica sejam 
devastados por epidemias, pois não possuem condições econômicas e técnicas de atuar, com presteza, nesses casos. Nota-se que permanece a necessidade de vacinas preventivas, tratamento de água, saneamento básico adequado, vigilância na produção de alimentos fresc os ou industrializados, facilmente transportados e comercializados. Nessa perspectiva, "a saúde deve ser encarada hoje como problema global, e que sua globalização é um bem pelo qual há de se trabalhar de modo explícito e programado" (Berlinguer, 1999). Ressalta-se que não apenas as doenças infecciosas se espalharam com a globalização, mas também as crônicas, ligadas ao modo de vida, à cultura, aos hábitos alimentares e à falta de higiene.

Um dos caminhos que pode contribuir para a compreensão dos problemas que se estabelecem nessa relação "globalização econômica e saúde" é a proposição ou utilização de metodologias de pesquisa que permitam perceber, com robustez, essas relações. A matriz, ou metodologia Peir (Pressão-Estado-Impacto-Resposta), foi pensada para proporcionar um mecanismo geral para analisar problemas ambientais, trazendo a ideia de que o ambiente é um sistema de múltiplas interações, de acordo com Ariza e Araujo Neto (2010). Segundo os autores, “a metodologia é vantajosa porque é facilmente ajustável a diferentes realidades e, assim, pode ser um importante instrumento na gestão pública, principalmente por mostrar a ligação entre os diversos elementos que compõem o sistema ambiental" (Ariza; Araujo Neto, 2010, p. 133). Além desses pesquisadores, outros têm utilizado a metodologia Peir com foco ambiental (Botto et al., 2005; Nakagomi, 2012; Silva; Cândido, 2012). Neste artigo, propõe-se apresentar a metodologia com abordagem na saúde, ou seja, mostrar o que está acontecendo com essa área por meio de análises das ações do Estado, em âmbito local e nacional, bem como identificar as forças e pressões que estão atuando nesse contexto, qual impacto têm gerado em termos de saúde/qualidade de vida da população, quais as respostas da população e do Estado a essas situações e o que pode acontecer se não houver ação.

Para demonstrar nossa proposição utilizamos como estudo de caso uma pequena cidade da Amazônia Legal ${ }^{1}$, Ponta de Pedras, Pará, por ser um laboratório inesgotável de situações urbanas típicas de países de economia periférica. A pesquisa partiu de levantamentos de dados primários sobre o acesso dos moradores a infraestrutura básica e serviços básicos de saúde e procurou entender a relação entre aspectos de urbanização e a saúde da população nessa cidade.

Para desenvolver este estudo foram coletados dados de campo ${ }^{2}$ no período entre janeiro e julho de 2016, por meio da aplicação de questionários aos moradores da área urbana de Ponta de Pedras, e de informações do Instituto Brasileiro de Geografia e Estatística (IBGE), assim como dados de outros órgãos do poder público local. Em um primeiro momento, foram aplicados formulários em 10\% dos domicílios urbanos, em todos os setores censitários urbanos, distribuídos por setor proporcionalmente ao número de domicílios existentes. Entretanto, neste artigo apresenta-se uma comparação apenas entre os dois ambientes predominantes na cidade, de terra firma e de várzea, que fazem parte de dois setores censitários, ou seja, foram utilizados os dados referentes apenas a dois setores censitários como exemplo dos dois ambientes citados.

Por meio dessa comparação foi possível questionar se a situação do ambiente, associada às condições de infraestrutura e habitabilidade, interfere no perfil de saúde dos moradores. Dessa forma, analisaram-se os dados obtidos apenas nesses dois setores, 20 e 22, em que foram aplicados formulários em 31 e 30 domicílios urbanos, respectivamente, que representaram em torno de $10 \%$ do total de domicílios desses setores ${ }^{3}$.

Os formulários continham dados como situações socioeconômicas, condições de saúde e serviços de infraestrutura disponíveis, entre eles, os relativos ao acesso a saúde, saneamento básico e água potável.

\footnotetext{
1 A Amazônia Legal, também denominada de Amazônia Brasileira, foi instituída pela Lei nº 1.806, de 6 de janeiro de 1953 (Brasil,1966a), estabelecida no artigo $2^{\circ}$ da lei ${ }^{0} 5.173$, de 27 de outubro de 1966 (Brasil,1966b), durante o Governo Vargas. A região representa $59 \%$ do território brasileiro, distribuindo-se por 771 municípios.

2 Esta pesquisa foi aprovada pelo Comitê de Ética da Faculdade de Saúde Pública da Universidade de São Paulo (USP) sob o número $099377 / 2015$.

3 De acordo com o IBGE (2011), os setores estudados, 20 e 22, possuíam no Censo de 2010279 e 268 domicílios, respectivamente.
} 
A matriz Peir foi utilizada como instrumento de análise, adaptada para realidade de uma pequena cidade, como será explicado posteriormente.

\section{0 urbano das pequenas cidades da Amazônia}

As realidades das pequenas cidades da Amazônia revelam especificidades. Segundo Oliveira (2006 p. 2729), "a vida nas cidades Amazônicas está ligada ao rio e à floresta. Transpondo-os, surgem os aglomerados de casas simples que, vista uma vez, nunca mais serão esquecidas”. Em 2010 as pequenas cidades representavam 78,2\% do total de cidades da Amazônia Legal, segundo dados do IBGE (2011). Elas possuem precariedade de desenvolvimento devido à baixa capacidade de geração de recursos, com uma forte dependência de repasses da União. Contudo, essas cidades continuam a atrair população, em especial das comunidades ribeirinhas, pois se apresentam como possibilidades de acesso a serviços e oportunidade de empregos em uma região onde o rural se mostra carente de infraestrutura e serviços básicos, além de não apresentar oportunidades de geração de renda (Costa; Brondízio, 2009). Para Castro, (2008, p. 11) “a interação entre os processos locais e globais na Amazônia Legal busca conexões lógicas que permitam entender como os efeitos da globalização, cuja dinâmica principal se dá em um complexo mercado transnacional, pode interferir nas ações de atores locais e na pressão sobre os recursos naturais".

O processo histórico e a consolidação das cidades da Amazônia no Brasil contam com a participação de portugueses, ingleses e franceses. A região vivenciou um imenso fluxo comercial de mercadorias típicas, como ervas medicinais aromáticas, drogas do sertão e frutas, muitas delas nativas. Nesse aspecto a geografia da Bacia Amazônica contribuiu para o processo exploratório. "Portugal percebendo o potencial lucrativo fundou a cidade naquele local para se apropriar destes recursos naturais" (Andrade, 2014, p. 97).

A região amazônica sempre teve um papel importante na economia extrativista. Durante a expansão e comercialização da borracha, uma nova classe econômica se estabilizou na região: seringueiros, fazendeiros e atravessadores. Esse ciclo inseriu a Amazônia na economia mundial, o que resultou em grandes conflitos fundiários e sociais, sobretudo no caso da produção do açaí. Segundo Andrade (2014, p. 102), "começou no final de 1990, com a exportação e internacionalização do produto para os EUA, por dois turistas americanos que ao levar o produto para o exterior fizeram sucesso".

Para Oliveira (2006, p. 28), "as pequenas cidades amazônicas apresentam essa contradição: são articuladas a relações pretéritas caracterizadas pela inércia e, ao mesmo tempo, articuladas a dinamicidades contemporâneas que as ligam ao mundo, especialmente a partir da biodiversidade e da sociodiversidade”. 0 processo de globalização possibilita inserções, contudo exige um dinamismo que muitas vezes não condiz com a realidade local, o que predispõe desgastes ambientais, sociais e, por vezes, econômicos que impactam de maneira direta ou indireta a população. A metodologia Peir é um instrumento de análise que subsidia a avaliação desse tipo de processo.

\section{A metodologia Peir nos estudos da saúde das pequenas cidades da Amazônia: Ponta de Pedras}

A metodologia Peir foi adaptada pelo Programa das Nações Unidas para o Meio Ambiente (Pnuma) e inicialmente desenvolvida como instrumento de análise teórica ambiental pela Organização para Cooperação e Desenvolvimento Econômico (OCDE). Essa organização é composta por mais de trinta países desenvolvidos e industrializados que tiveram um papel pioneiro, em 1979, na elaboração de uma proposta de estado do meio ambiente, com base nos indicadores ambientais (OECD, 2003). Kristensen (2004), ao pesquisar essa metodologia, afirma que

Na recomendação à Agência Europeia do Ambiente (AEA) sobre como devem proceder com o desenvolvimento de uma estratégia para a Avaliação Ambiental Integrada, o Instituto Nacional de Saúde Pública e Meio Ambiente propôs o uso de um quadro, que distinguiu forças motrizes, as pressões, estados, impactos e respostas. Isso ficou conhecido como o quadro Peir e desde então tem sido mais amplamente adotado pela AEA, agindo como uma abordagem integrada para 
geração de relatórios, por exemplo, em relatórios sobre a situação do Ambiente da AEA. O quadro é visto como dando uma estrutura na qual apresenta os indicadores necessários para permitir um feedback para os decisores políticos sobre a qualidade ambiental e o impacto resultante das escolhas políticas feitas, ou a adoptar no futuro (Kristensen, 2004, p. 1, tradução nossa) ${ }^{4}$.

Philippi Junior e Malheiros (2012) comentam que o modelo Peir foi desenvolvido pelo estatístico canadense Anthony Friends na década de 1970 e consiste em avaliar um sistema a partir de três aspectos: o estado da situação; as forças e atividades que estão mantendo ou causando o estado atual; e as medidas que estão sendo tomadas para melhoria, manutenção ou reversão do quadro encontrado.

Segundo Kristensen (2004), a metodologia Peir apresenta estágios de relações causais que começam com força motriz (dos setores econômicos, das atividades humanas), por meio de pressões (emissões, falta de abastecimento de água) e estados (físico, químico e biológico), causando impactos sobre ecossistemas, saúde e funções humanas e respostas das políticas (sociedade, fixação de metas, indicadores, poder público), relações essas que estão demonstradas na Figura 1.

De acordo com Ariza e Araujo Neto (2010), no modelo proposto na metodologia Peir

as atividades humanas exercem pressão no ambiente que alteram a qualidade e quantidade dos recursos naturais. As pressões induzem mudanças na situação do ambiente, como por exemplo, aumento no nível de poluente, alteração de uso do solo etc. Então a sociedade responde a essas mudanças por meio de políticas ambientais, econômicas e programas para mitigar ou recuperar os danos causados. (Ariza; Araujo Neto, 2010, p. 133)

Embora esse modelo metodológico possa indicar uma interação linear entre as atividades desenvolvidas pela sociedade, deve-se levar em consideração o nível de importância dos indicadores estudados, assim como as especificidades do território. Essa metodologia contribuiu e deve ser utilizada nos estudos devido a sua simplicidade e facilidade de interpretação, o que permite aplicação em diferentes análises de variáveis e atividades humanas (Carvalho et al., 2009).

\section{Figura I - Quadro conceitual da metodologia Peir}

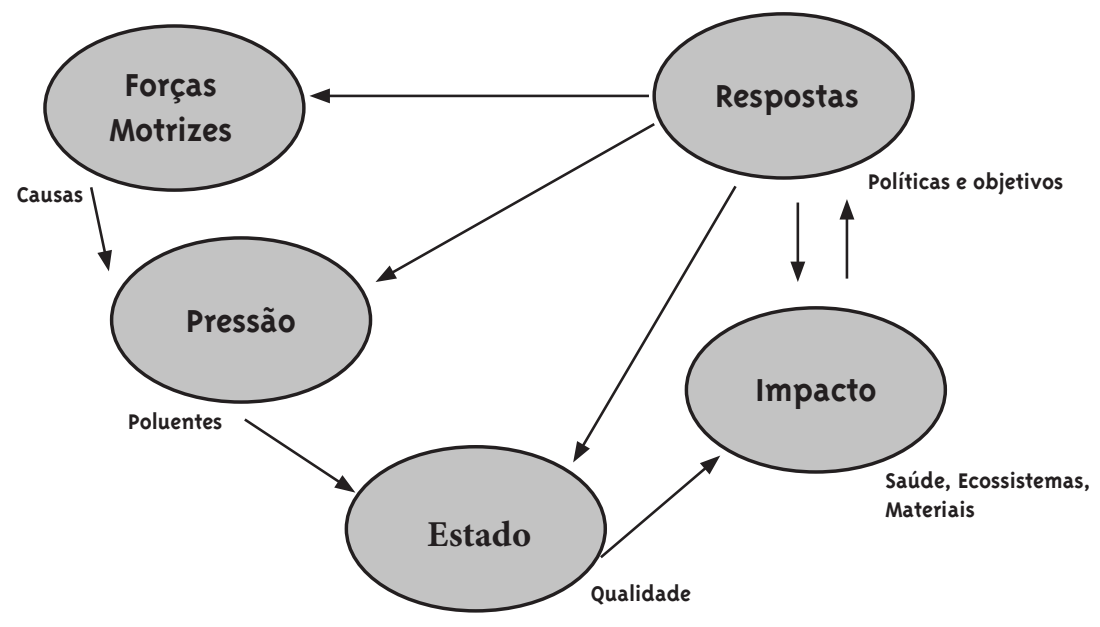

Fonte: Adaptado de Kristensen, 2004

4 In recommendation to the European Environment Agency (EEA) on how they should proceed with the development of a strategy for Integrated Environmental Assessment, RIVM - National Institute of Public Health and Environment, proposed the use of a framework, which distinguished driving forces, pressures, states, impacts and responses. This became known as the DPSIR framework and has since been more widely adopted by the EEA, acting as an integrated approach for reporting, e.g. in the EEA's State of the Environment Reports. The framework is seen as giving a structure within which to present the indicators needed to enable feedback to policy makers on environmental quality and the resulting impact of the political choices made, or to be made in the future. 
Para Netto et al. (2009), aspectos ambientais combinam diferentes modos de uso da terra, mas associados aos determinantes sociais contribuem para compreender as iniquidades em relação ao perfil de saúde de uma população.

Nesse sentido, a metodologia Peir possibilita uma interconexão entre ambiente e saúde ao se estudar a integração de um ou mais indicadores de qualidade de vida em saúde relacionados às questões ambientais e socioeconômicas. Segundo Oliveira e Faria (2012, p. 451), compreender as relações da saúde humana com o meio ambiente, a partir do reconhecimento dos efeitos da ação antrópica e dos reflexos das condições ambientais na saúde da população, é indispensável para subsidiar a definição de políticas e estratégias de diversos setores.

Neste artigo não será aprofundada a abordagem sobre indicadores. No entanto, ressalta-se que eles nos mostram valores e informações sobre certos fenômenos que ocorrem nos ambientes urbanos, os quais precisam ser ponderados em estudos de saúde e ambiente. A
OCDE desenvolveu trabalhos com várias categorias de indicadores, cada um de acordo com o propósito e a estrutura específica para a metodologia Peir.

O Quadro 1 apresenta como a metodologia Peir, que permite um diálogo entre a geografia da saúde e as demais ciências, foi utilizada com o objetivo de avaliar os impactos das alterações do ambiente no modo de vida e na saúde da população estudada. Neste artigo utilizamos a interconexão de ambiente e saúde, analisada com base em força motriz, pressão e estado a partir dos dados obtidos na cidade de Ponta de Pedras, localizada na Ilha do Marajó (PA). Dentro do grupo de impactos sobre ambiente e saúde, de acordo com a OECD (2003), os componentes da Peir são considerados para o município pesquisado. Tendo em vista que tratamos de uma pequena cidade da Amazônia, a qual apresenta problemas também vislumbrados em outras realidades urbanas, foram incorporadas adaptações à metodologia em relação aos indicadores de força motriz, pressão e estado.

Quadro I - Metodologia Peir

\begin{tabular}{|c|c|c|}
\hline $\begin{array}{l}\text { Metodologia } \\
\text { Peir }\end{array}$ & $\begin{array}{c}\text { Impactos ocasionados e avaliados pela } \\
\text { metodologia Peir }\end{array}$ & Adaptação para a área de estudo - dados utilizados \\
\hline Força motriz & $\begin{array}{l}\text { São as necessidades da população, } \\
\text { caracterizadas como básicas e } \\
\text { secundárias. }\end{array}$ & $\begin{array}{l}\text { Número de habitantes urbanos, estrutura etária, nível } \\
\text { educacional, sistema de esgoto, abastecimento de água, } \\
\text { uso de energia pública e por domicílios. }\end{array}$ \\
\hline Pressão & $\begin{array}{l}\text { Pressões das atividades humanas sobre } \\
\text { o ambiente (água, ar), incluindo a } \\
\text { quantidade e qualidade dos recursos } \\
\text { naturais disponiveis e utilizados, que } \\
\text { podem causar problemas ambientais. }\end{array}$ & $\begin{array}{l}\text { Ocupação urbana > crescimento urbano desordenado; } \\
\text { emissão de resíduos sólidos (esgoto e lixo)5. }\end{array}$ \\
\hline Estado & $\begin{array}{l}\text { Mostram a atual situação do meio } \\
\text { ambiente e as consequências para a } \\
\text { saúde. }\end{array}$ & $\begin{array}{l}\text { Referem-se à qualidade do ambiente e à quantidade dos } \\
\text { recursos naturais disponíveis e utilizados. }\end{array}$ \\
\hline Impacto & $\begin{array}{l}\text { Fatores socioambientais e biológicos que } \\
\text { afetam a saúde e qualidade de vida. }\end{array}$ & $\begin{array}{l}\text { Permite analisar a interferência na condição de saúde dos } \\
\text { moradores, como as doenças relacionadas à falta de água } \\
\text { tratada e saneamento básico comprometem a saúde da } \\
\text { população exposta. }\end{array}$ \\
\hline Resposta & $\begin{array}{l}\text { São atuações coletivas ou individuais } \\
\text { que resultaram em diferentes medidas e } \\
\text { políticas para esse cenário }\end{array}$ & $\begin{array}{l}\text { As mobilizações da população para tentar resolver seus } \\
\text { problemas, a fim de gerar melhorias no sistema de saúde. }\end{array}$ \\
\hline
\end{tabular}

Fonte: Adaptado de Kristensen, 2004

5 Resíduos sólidos são "material, substância, objeto ou bem descartado resultante de atividades humanas em sociedade, a cuja destinação final se procede, se propõe proceder ou se está obrigado a proceder, no estado sólido ou semissólido, bem como gases contidos em recipientes e líquidos cujas particularidades tornem inviável o seu lançamento na rede pública de esgotos ou em corpos d’água, ou exijam para isso soluções técnica ou economicamente inviáveis em face da melhor tecnologia disponível” (0liveira, 2015, p. 48). 
Em relação à força motriz, incorporaram-se os dados de acesso dos domicílios urbanos à rede de água e esgoto, considerando os dados primários, coletados em campo. Nessa análise, compararam-se os dados primários com os secundários, do Censo de 2010. Quanto à pressão, em vez de mapear o uso da terra, optou-se por utilizar um mapa de crescimento urbano dos setores estudados nas últimas quatro décadas, comparando esse crescimento com o acesso dos domicílios à rede de abastecimento de água e de coleta de esgoto e lixo. Em relação ao estado, optou-se por utilizar dados sobre a disponibilidade de áreas para ocupação, considerando se o setor está ou não esgotado em termos de oferta de terra, a qualidade dessa terra e como isso pode influenciar no crescimento da cidade. Todas essas informações são determinantes das condições de saúde dos moradores. Por exemplo, a distribuição de água é um condicionante de política pública de saneamento básico, que interfere de maneira significativa na saúde.

\section{Resultados e discussões}

\section{Ponta de Pedras: uma pequena cidade da rede urbana da Amazônia}

Desde o início dos anos 1970, a Amazônia Legal passou por grandes modificações urbanas, em especial devido ao aumento da população. Dessa forma, as forças motrizes e as pressões, definidas na metodologia Peir para o caso analisado, também sofrem alterações. Dados do relatório da Organização Pan-Americana da Saúde (Brasil, 2004) mostram que a população da Amazônia Legal cresceu 44,3\%, ao passo que no país o aumento populacional foi de $28,9 \%$. Ao avaliar a evolução da população urbana na região amazônica, dados demonstram um crescimento considerável nos últimos cinquenta anos em vários municípios. Os dados demográficos apontam um processo crescente da ocupação urbana na região Norte do Brasil. Ponta de Pedras é um exemplo dessas muitas cidades que passaram por transformações ao longo das décadas. De acordo com Costa et al. (2016),

Esse processo de urbanização, da produção do espaço urbano na Região Amazônica pode ser considerada igualmente portadora de contradições e geradora de conflitos entre a população e o ambiente sobre o qual se instala. Muitas cidades dessa Região se instalaram sobre áreas de várzea, ambiente esse acessível na navegabilidade da Região e que compõem o dia a dia da população ribeirinha.

Localizada na Ilha de Marajó, na região estuarina do Rio Amazonas, Ponta de Pedras (Figura 2) se insere no contexto das pequenas cidades da Amazônia. É considerada pequena em termos demográficos, do ponto de vista de infraestrutura e da oferta de serviços urbanos. De acordo com Costa et al. (2016, p. 121), esse "crescimento urbano foi, particularmente, expressivo entre 1991 e 2010, quando a área urbana cresceu $126 \%$, e a população urbana mais que $111 \%$. Observa-se, nesse período, uma intensificação da importância do açaí no mercado mundial e de sua produção no município".

O aumento da população da cidade de Ponta de Pedras é acompanhado pelo aumento na produção de açaí no município. Dados estatísticos do IBGE (2010) demonstram que a produção de açaí no ano de 2001 atingiu 123 mil toneladas, com valor total de mercado em 83,5 milhões de reais, sendo que a região Norte e o estado do Pará foram os grandes responsáveis por esse resultado. Em 2011 a produção foi de 215.381 toneladas, gerando divisas de R\$ 304,6 milhões; a região Norte contribuiu com 203.112 toneladas, e o Pará com 109.345. O hábito de consumir açaí virou um modismo tanto no Brasil quanto no exterior, segundo dados da Secretaria de Estado de Agricultura do SAGRI (2013) ${ }^{6}$. No Marajó poucos municípios se destacam pela produção de açaí e palmito. Ponta de Pedras foi responsável por 30,21\% do total desses produtos no estado do Pará (Barbosa, 2012). Contudo, mesmo sendo um recurso

6 No Pará há registros de aumento da área plantada na última década, passando de 18.479 ha em 2001, para 80.092 ha em 2011 (Sagri, 2013). O mercado atual de frutos está em plena expansão no Brasil e no exterior, o que vem estimulando muitos plantios comerciais no Pará, na região amazônica e em outras regiões brasileiras (Sagri, 2013). 
Figura 2 - Município de Ponta de Pedras por setor censitário

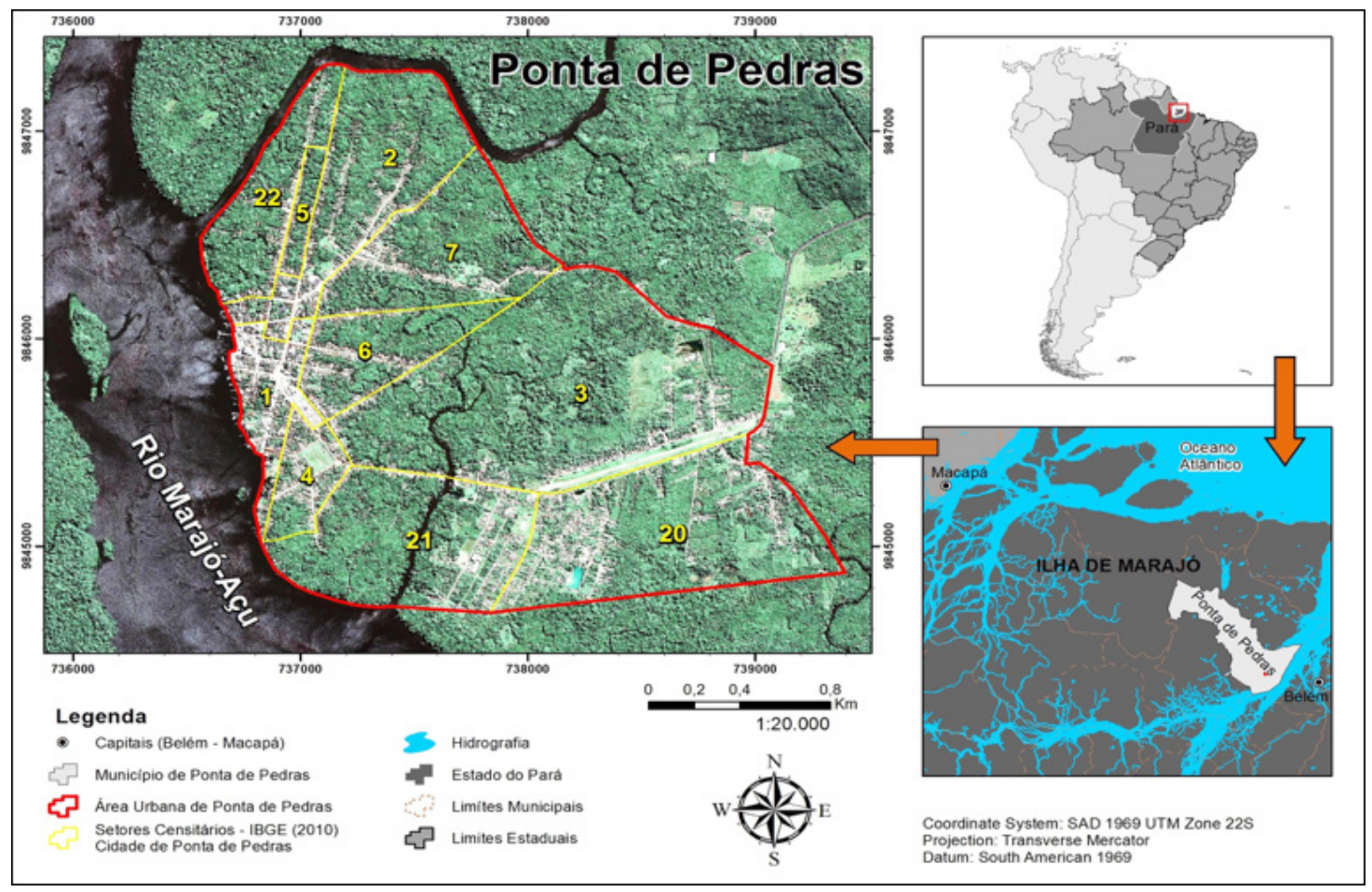

valioso e comercializado no mercado nacional e global, na Ilha do Marajó e em Ponta de Pedras a produção e comercialização do açaí como produto extrativista não se reflete em melhorias econômicas ou sociais significativas para os trabalhadores locais. Estudo realizado por Vedoveto (2008, p. 4) corrobora a importância do açaí na base alimentar e para a economia do Pará e do país.

O Estado do Pará é o maior produtor e consumidor de açaí, a polpa do açaí é item complementar se não básico das refeições diárias do paraense, principalmente entre as famílias de baixa renda. A Palmeira é uma das espécies mais promissoras das áreas de várzea do estuário amazônico e rende monetariamente valores acima da medida salarial do Estado. Nas áreas onde se concentram seus estoques naturais, é o principal produto extrativista em nível alimentar e socioeconômico.

O município de Ponta de Pedras é formado por terra firme e várzea, a qual sofre influência do Rio Marajó-Açu. A malha hídrica ligada a esse rio sofre alterações durante o verão e o inverno na região, o que altera a dinâmica da cidade e de seus moradores.

De acordo com o Censo de 2010 (IBGE, 2011), o município contabilizava 26 mil habitantes, sendo que 49\% residiam na área urbana. A cidade de Ponta de Pedras, apesar de apresentar uma dinâmica espacial, não tem políticas públicas que proporcionem aos moradores um atendimento adequado de serviços urbanos de infraestrutura básica, conforme constataram os estudos de Costa et al. (2012, p. 58).

Os setores censitários utilizados nesta pesquisa são representantes de dois ambientes da cidade: a várzea e a terra firme. Esta se constitui de áreas que não sofrem interferência direta da variação do nível do rio e da maré. Em contraposição, a área de várzea é alagada constantemente, como resultado da dinâmica de variação da maré. A várzea, segundo Costa et al. (2016, p. 115), "nas cidades da Amazônia torna-se um espaço de sobrevivência e dissemina hábitos e comportamentos". Na Figura 3 é possível observar fotografias obtidas em campo dos setores 20 e 22, para exemplificar como esses dois ambientes, fisicamente, são diferenciados. Na 
Figura 3 - Fotografias dos setores 20 e 22, nas quais é possível observar que o setor 20 não está exposto às variações da maré como o setor 22 , que está sobre a várzea

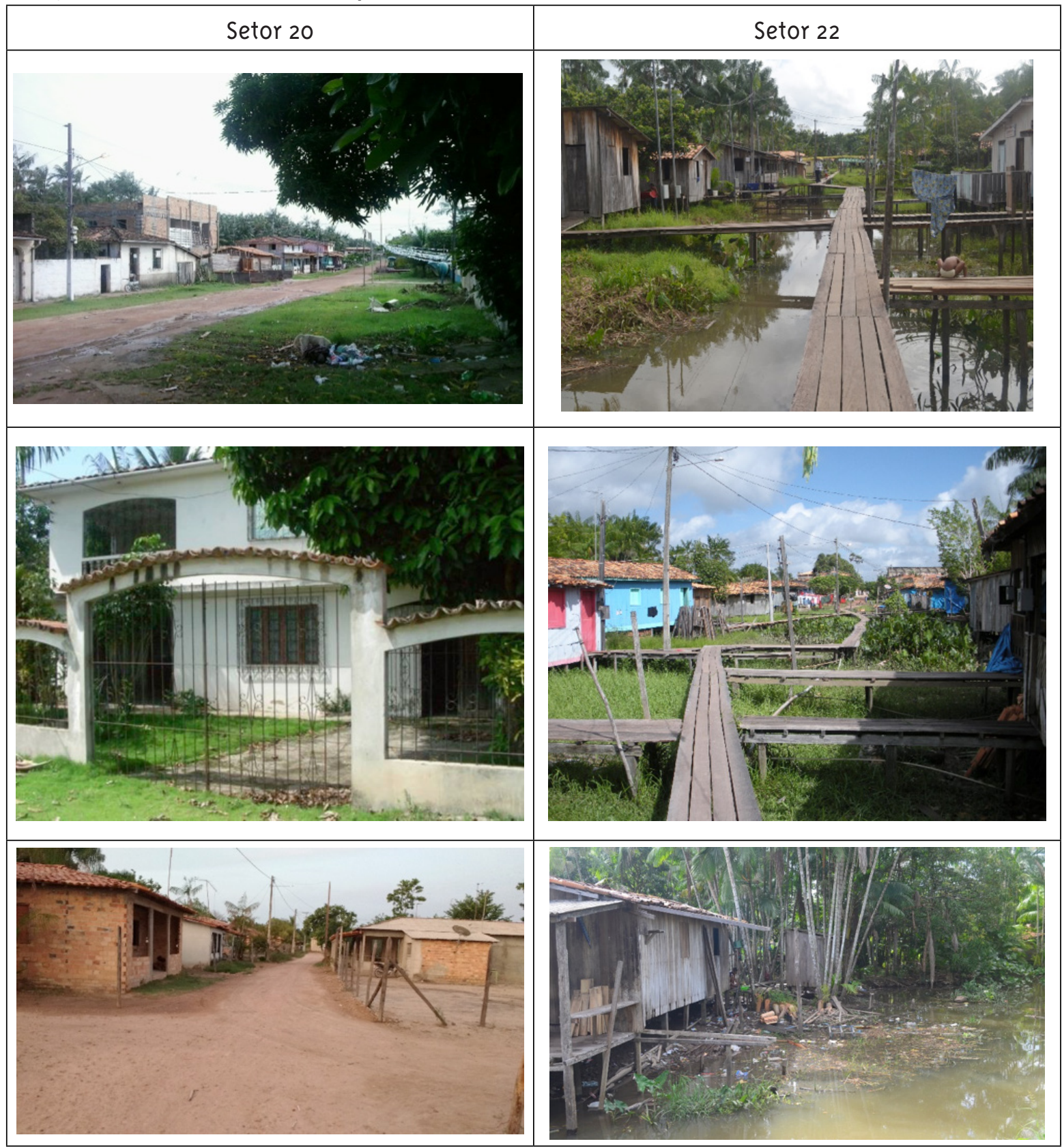

várzea os moradores possuem contato direto com a água das marés, e predominam casas de palafita. Na terra firme as construções são diferenciadas, e predomina o concreto como material construtivo.

\section{Forças motrizes}

Nesta pesquisa foram consideradas como forças motrizes as necessidades da população, 
caracterizadas como básicas e secundárias. Segundo Kristensen (2004, p. 2), alguns exemplos de forças motrizes primárias para um indivíduo seriam a necessidade de abrigo, comida e água, e secundárias, a necessidade de mobilidade e cultura.

Nesse sentido, embasados nas discussões de Silva e Cândido (2012), Botto et al. (2005), Nakagomi (2012) e Kristensen (2004), definimos as variáveis número de habitantes urbanos, faixa etária, nível educacional, acesso à rede de esgoto, tipo de abastecimento de água e o uso de energia pública por domicílios como fatores que atenderiam essas necessidades básicas.

Em relação à população residente, os setores 20 (terra firme) e 22 (várzea) possuem 9\% e 10\% do total dos moradores residentes na área urbana. Ou seja, o setor 22, que possui ocupação mais antiga (após 1990), ocupa 9\% da área total urbana e assenta-se na área de várzea. O setor 20, de ocupação mais recente (após meados dos anos 1990), possui uma área física maior e detém $9 \%$ do total de moradores urbanos. A área ocupada por ambos os setores é significativamente diferente. 0 setor 20 tem uma área de o,78 km2, e o 22 possui uma área de o,42 km2. Considerando a área urbana existente em cada setor, observa-se que ainda há uma disponibilidade de terreno a ser ocupado, ou seja, ainda existe área livre nos dois setores: $72 \%$ e 71\%, respectivamente. Apenas uma menção à situação do setor 22, considerando ser essa uma área de várzea, o que torna sua ocupação preocupante. Há ainda mata, muito açaizeiro, e o local está sujeito a alagamentos diários em função da variação da maré. Portanto, apesar da densidade demográfica não ser uma força motriz nesse momento, a ocupação e as características físicas dos setores precisam ser consideradas.

Tendo em vista o perfil socioeconômico dos entrevistados nos dois setores censitários estudados, a maioria das famílias ( $87 \%$ e 93\%, respectivamente) possui renda mensal abaixo de dois salários-mínimos. Há uma dependência muito grande por parte desses moradores dos benefícios governamentais de transferência de renda, como o Bolsa Família e o Seguro Defeso, para complementar a renda. Para o nível educacional, os dados coletados mostram uma situação de carência. No setor 20, 29\% dos entrevistados são analfabetos e $45 \%$ possuem o ensino fundamental incompleto. No setor 22 a situação se apresenta um pouco diferente, sendo que $7 \%$ são analfabetos e $47 \%$ possuem o ensino fundamental incompleto. Considerando essa força motriz de característica socioeconômica, o setor 22 apresenta uma situação social mais precária do que o 20. Ou seja, há famílias com situação de renda e nível educacional não tão críticas no setor de terra firme, se comparado à área de várzea, apesar de os resultados não serem considerados excelentes.

Quando se observa a faixa etária dos entrevistados (chefes de família), ressalta-se outra situação interessante: no setor 20, 71\% dos entrevistados possuem entre vinte e quarenta anos, enquanto no setor 22, para essa mesma faixa, há $50 \%$ dos entrevistados; entretanto, $44 \%$ dos chefes de família do setor 22 possuem mais de cinquenta anos, e no setor 20, eles somam 19\%. Ou seja, há uma predominância de pessoas mais velhas no setor 22, o qual possui maior vulnerabilidade social e econômica. Ressalta-se que a área de várzea é mais frágil e exposta a problemas ambientais do que o setor de terra firme.

Outra força motriz importante, que se torna crítica quando associada às outras forças apresentadas, é o acesso à infraestrutura básica, a qual é muito precária em ambos os setores, com pequenas diferenças. 0 setor 20 possui $13 \%$ dos domicílios com acesso à rede de água Companhia de Saneamento Básico do Pará (Cosanpa), e o setor 22, 93\%. Uma razão para a diferença no acesso ao serviço do sistema de abastecimento de água referese ao tempo de ocupação dos setores e consequente investimento em infraestrutura básica. No setor 20, $13 \%$ dos domicílios possuem acesso à agua coletada em poço, ocorrência inexistente no setor $22 \mathrm{em}$ função das características físicas do sítio, pois o constante alagamento da várzea impede a obtenção de água por essa via.

Em relação ao acesso ao sistema de coleta de esgoto - coleta apenas, pois não há tratamento de esgoto na cidade-, os dados apresentados também desenham um quadro preocupante: apenas 3\% e $7 \%$ dos domicílios dos setores 20 e 22, respectivamente, estão conectados ao sistema de coleta de esgoto. Para esses mesmos 
setores, $87 \%$ e $30 \%$ dos domicílios possuem fossa séptica. Segundo relatos dos entrevistados, $100 \%$ dos domicílios possuem energia elétrica.

Os dados primários, coletados em campo, aproximam-se dos disponibilizados pelo Censo de 2010, com poucas discrepâncias. Para os setores $20 \mathrm{e}$ 22, 54\% e 74\% dos domicílios possuem acesso à rede de água, e o\% e 11\% dos domicílios estão conectados à rede de coleta de esgoto.

Na Figura 4 são apresentadas algumas fotografias obtidas durante o trabalho de campo na cidade de Ponta de Pedras, as quais mostram os setores e o acesso à infraestrutura como exemplo dessas forças motrizes na cidade.

\section{Figura 4 - Imagens do setor 22 que exemplificam a situação alagamento periódico da várzea (a) e banheiro localizado fora de domicílio, sem acesso à rede de esgoto (b)}

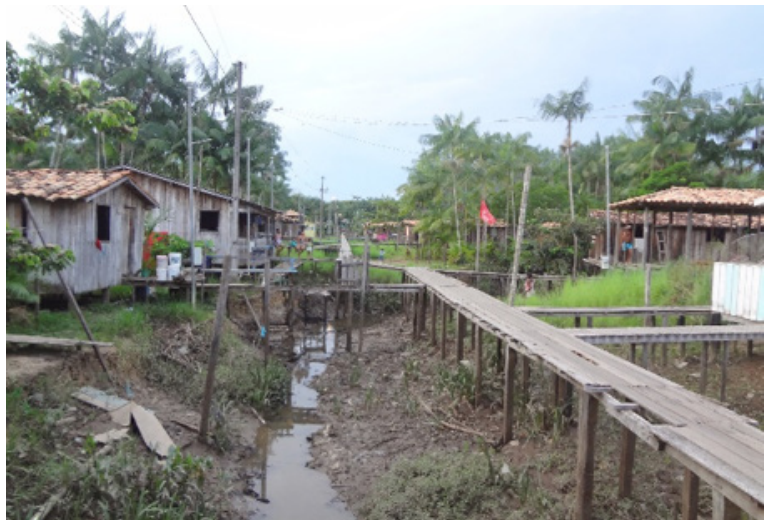

(a)

\section{Pressão}

Segundo Kirstensen (2004), a pressão é definida como ação das atividades humanas que interferem no ambiente (água, ar), incluindo a quantidade e qualidade dos recursos naturais disponíveis e utilizados. Para esta pesquisa, os indicadores de pressão descrevem o crescimento urbano dos setores de várzea e terra firme, o que pode desencadear desestabilizações ambientais, socioeconômicas e na condição de saúde da população.

Nesse sentido, os setores censitários 20 e 22 (Figura 2) cresceram, entre 2000 e 2014, em torno de $461 \%$ e $370 \%$, respectivamente, apresentando a expansão urbana mais significativa de todos os setores. Assim, os aumentos populacionais e em área verificados na cidade, em particular nesses setores censitários, atuam como forças motrizes, mas ao mesmo tempo como pressões sobre o ambiente.

Um aspecto relacionado à pressão se refere à forma de descarte de resíduos sólidos no ambiente

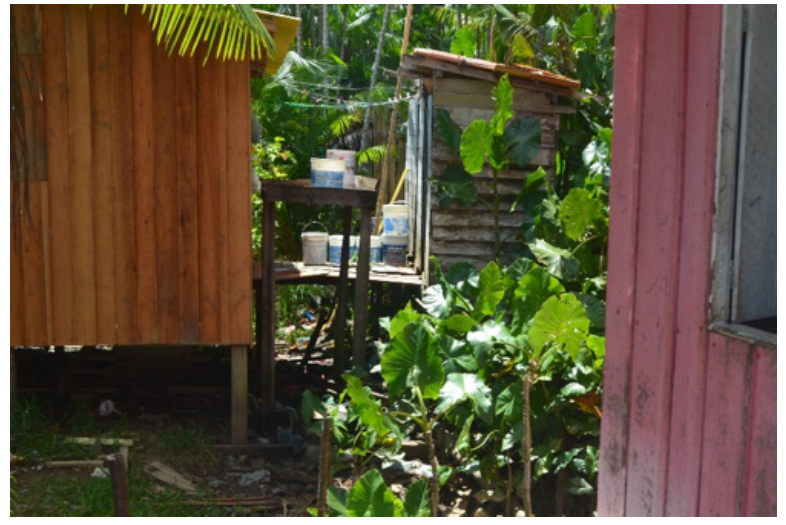

(b)

pelos moradores. De acordo com dados do Censo 2010 (IBGE, 2011), no setor 20 - de terra firme e mais distante da área central da cidade, comparando-se ao setor de várzea -, 2\% dos domicílios possuem coleta de lixo. No setor 22 essa situação é observada em $61 \%$ dos domicílios.

Apesar desses dados coletados pelo Censo, de acordo com Oliveira (2015) os resíduos sólidos produzidos pelas famílias residentes em áreas de várzea da cidade de Ponta de Pedras, incluindo o setor 22, segundo os moradores, são jogados diretamente na várzea ou queimados. Uma justificativa para esse comportamento é o fato de a coleta de resíduos não acontecer ou, quando acontece, não inclui a maioria da população da região (Figura 5). Segundo o autor, "Essa atitude, juntamente com uma parte da população que acredita que a maré leva o lixo embora, dificulta a criação de ações que possam amenizar o problema do lixo na várzea” (Oliveira, 2015, p. 47). Como demonstrado no item anterior, os efluentes domésticos exercem também uma importante pressão sobre o ambiente. 


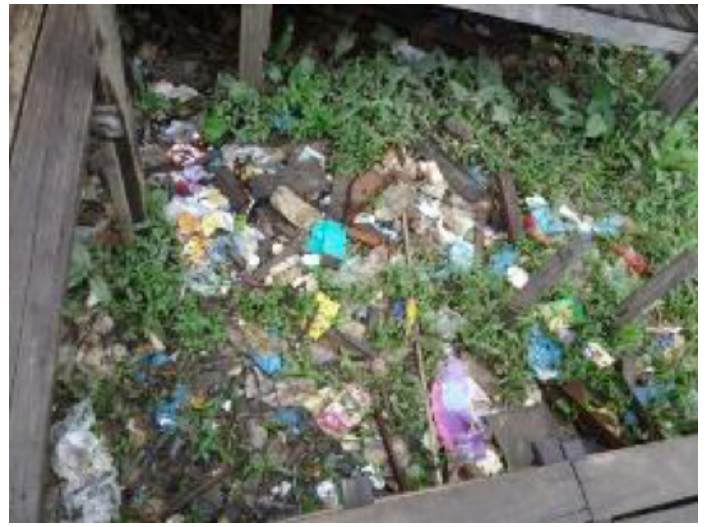

\section{Estado}

Os indicadores de estado retratam as implicações quali-quantitativas do ambiente, ressaltando os principais problemas observados para o ambiente e a população.

Para esta pesquisa assumiu-se estado como aquilo que está acontecendo com o meio ambiente e as consequências disso para a saúde. Segundo Kristensen (2004), refere-se à qualidade do ambiente e à quantidade dos recursos naturais disponíveis e utilizados. Neste artigo, considera-se uma intersecção entre pressão e estado na cidade de Ponta de Pedras, pois as pressões apresentadas anteriormente interferem na qualidade do ambiente e, dessa forma, trazem consequências à saúde da população.

Quando se analisam os dados de água, rede de esgoto e fossa, observa-se uma forte carência de infraestrutura e de saneamento básico. 0 esgoto frequentemente lançado nos igarapés, in natura, é uma realidade e, conforme observações em campo, reafirma a necessidade de investimentos em políticas de saneamento e de abastecimento de água. Nesse sentido, estado e ambiente se caracterizam pela má conservação dos recursos hídricos potáveis, o

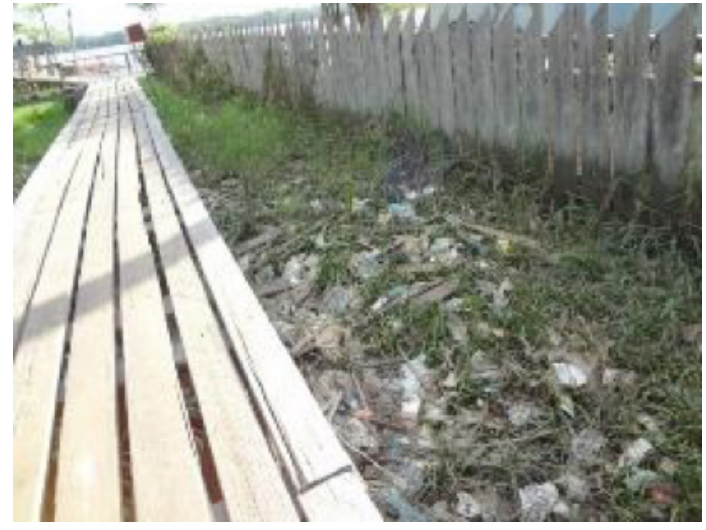

que se reflete na qualidade de saúde da população, assim como a existência de lixo a céu aberto, áreas desmatadas, animais de criação doméstica circulando livremente.

\section{Impacto}

Para Saunders (1983), as doenças estão relacionadas a clima, geografia, cultura, hábitos de higiene, além das formas de despejo de dejetos. A frequência e exposição de agentes patológicos presentes na água aumentam à medida que a população cresce nos ambientes urbanos, assim como se intensifica o uso desse recurso essencial à vida. Para Ribeiro (2006), as patologias responsáveis por um número elevado de óbitos são indicativas das condições de vida, meio ambiente e saúde.

As doenças transmitidas por veiculação hídrica na cidade de Ponta de Pedras foram citadas nas entrevistas em campo (Gráfico 1). Observando esses resultados e as possibilidades de a transmissão de doenças ${ }^{7}$ por meio da água ser um agravante, percebe-se a precariedade da saúde da população.

Para as duas doenças mencionadas, observou-se um maior número de casos no setor 22 (Figura 4). As áreas estudadas reúnem indicadores econômicos,

\footnotetext{
7 Há vários tipos de doenças que podem ser causadas pela água. São assim denominadas quando causadas por organismos ou outros contaminantes disseminados diretamente por meio da água. Em locais com saneamento básico deficiente (falta de água tratada, de rede de esgoto e/ou de alternativas adequadas para a deposição de dejetos humanos), doenças podem ocorrer devido à contaminação da água por esses dejetos, assim como pelo contato com esgoto despejado nas ruas ou nos córregos e rios. A escassez de água também pode causar doenças, pois impede uma higiene adequada. Incluem-se ainda na lista de doenças de transmissão hídrica aquelas causadas por insetos que se desenvolvem na água. Algumas dessas doenças possuem alto potencial de disseminação, com transmissão de pessoa para pessoa (via fecal-oral), aumentando assim sua propagação na comunidade. Podem também ser transmitidas por alimentos, devido a mãos mal lavadas de preparadores, portadores/assintomáticos ou doentes (São Paulo, 2009).
} 
educacionais e infraestruturais diferentes. 0 setor 20 é uma área de terra firme cuja maioria das casas (70\%) é de alvenaria; contudo, o abastecimento de água continua uma das principais reclamações dos moradores. Os entrevistados relataram que um dos graves problemas do município é, em especial na área urbana, o saneamento básico. Os moradores acreditam que a precariedade dessa infraestrutura é o principal fator da existência de doenças por veiculação hídrica, tais como dengue, virose e diarreia, que contaminam ou expõem crianças e idosos, grupos mais vulneráveis.

\section{Gráfico I - Doenças relacionadas à água, de acordo com a visão dos moradores de Ponta de Pedras, 2016}

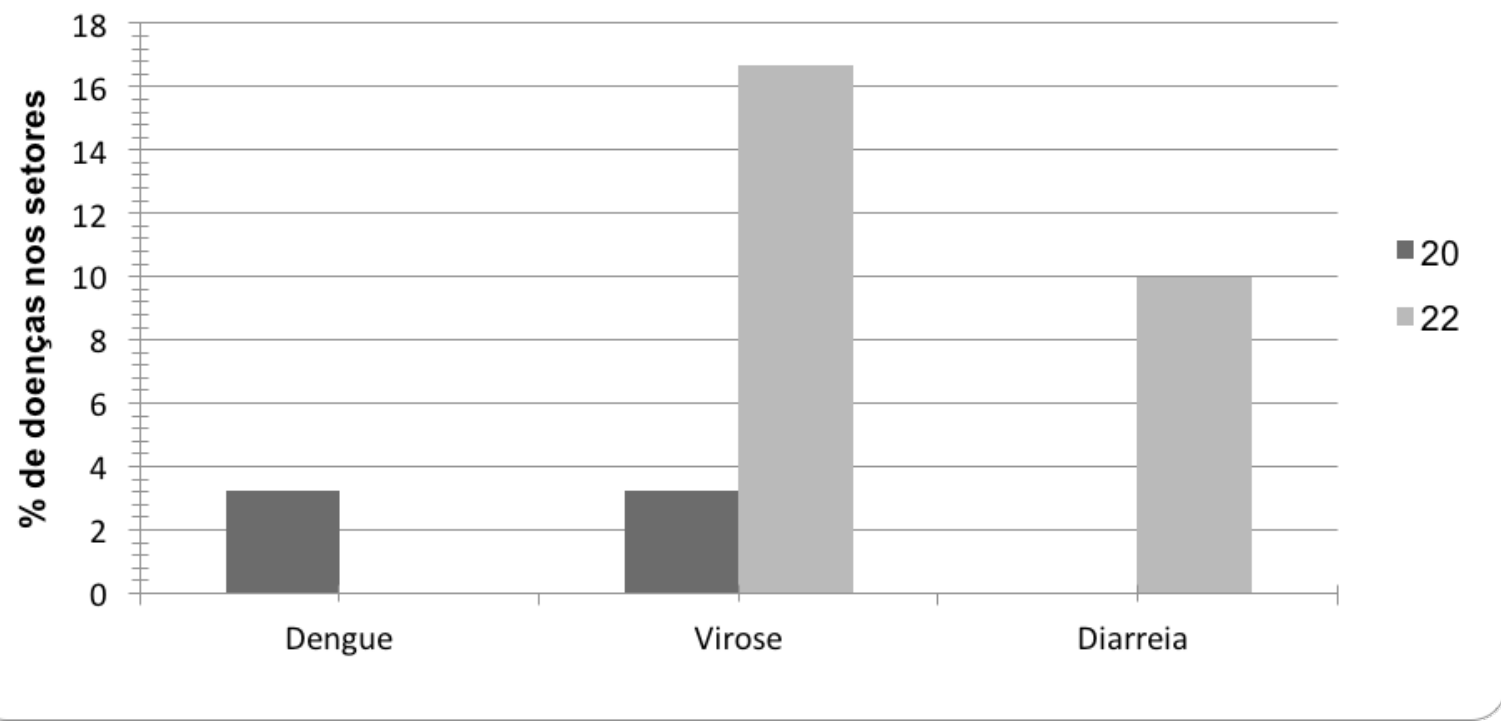

A metodologia Peir apresenta as inter-relações entre modificações ambientais e seus efeitos diretos sobre a saúde. Os dados relacionados à infraestrutura reforçam as reclamações dos moradores residentes nos dois setores e expõem a precariedade do abastecimento e tratamento de água, bem como dos hábitos de higiene. No formulário, na questão sobre limpeza da caixa d'água, observa-se que há uma baixa frequência de respostas que demonstrem cuidado nesse importante item de higiene (menos de 3\%).

Em janeiro de 2016, durante uma entrevista, o engenheiro responsável pela supervisão de serviços da Cosanpa na Ilha do Marajó relatou que há três anos a companhia não faz a análise da água; alegou motivos de logístico (dificuldade e alto custo do serviço), além da distância geográfica dos municípios ribeirinhos das cidades centrais como Belém, entre eles, Ponta de Pedras.

\section{Resposta}

Perguntou-se aos moradores se a água consumida era de boa qualidade. Os entrevistados nos dois setores apresentaram respostas diferenciadas (Figura 5). Para o setor 20, os moradores comentaram que possuem condições de higiene e saneamento básico precárias, e acreditam que a água tratada pela Cosanpa não é boa. Portanto, como resposta a essa situação, muitos moradores optam pelo tratamento da água com hipoclorito de sódio, distribuído nas Unidades Básicas de Saúde (UBS); outros, porém, acreditam que a água chega tratada a sua residência; e vários decidem filtrar o recurso, como pode ser observado no gráfico do Gráfico 2. 0 método de filtragem e o uso do hipoclorito são opções de tratamento da água, considerando a relação de custo/benefício. 
Considerando a situação analisada, infere-se que o setor 22 pode apresentar impactos maiores em relação à saúde da população por ser uma área de várzea e por apresentar maior pressão sobre o ambiente, como o crescimento urbano e o precário acesso à infraestrutura básica. Observou-se durante o trabalho de campo que não há respostas da população à problemática, não há mobilização dos moradores no sentido de formar associações ou promover reuniões com o poder público, de forma organizada, para lutar por mudanças. Ressalta-se também uma inoperância do poder público para resolver essas questões de forma imediata.

Nesse contexto, a resposta se resume a pequenas ações, individuais, como a mencionada anteriormente sobre o tratamento da água.

\section{Gráfico 2 - Respostas sobre o tipo de tratamento de água para consumo utilizado pelos moradores}

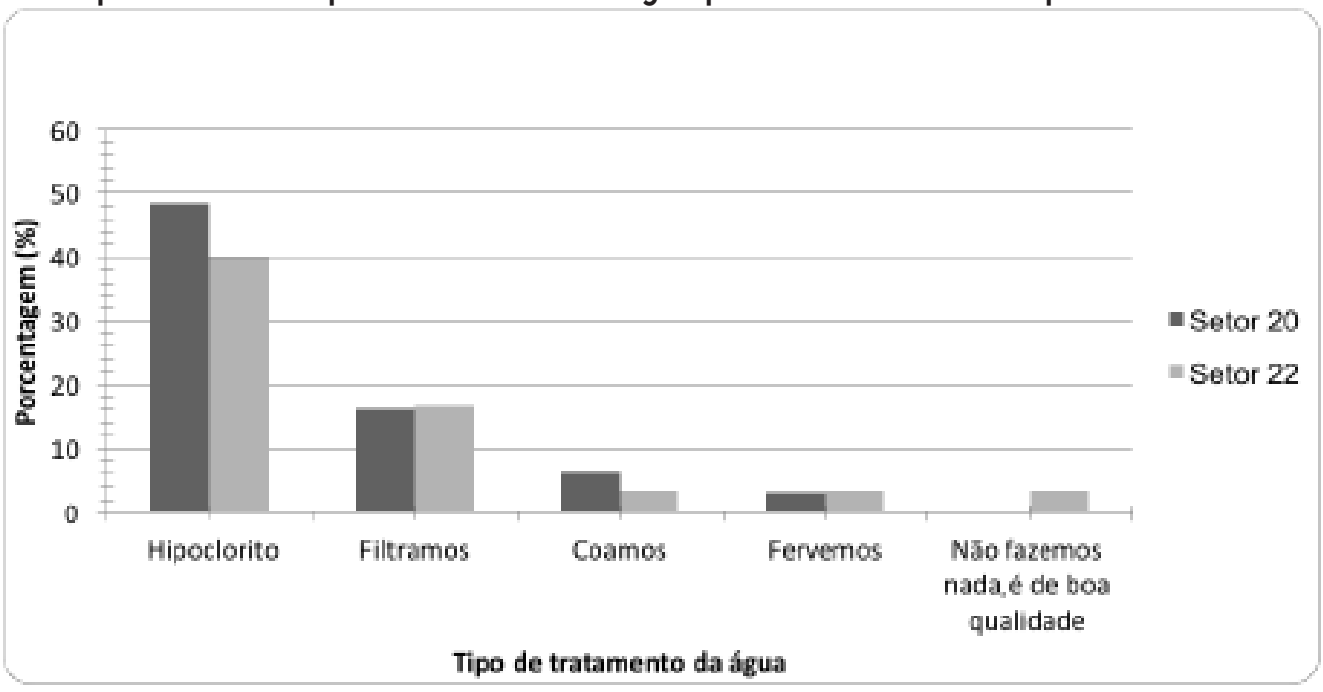

\section{Considerações Finais}

A análise dos fatores apresentados nos permitiu elaborar uma avaliação integrada de apenas três elementos da metodologia Peir. Em Ponta de Pedras, as forças motrizes são representadas pelo crescimento da área urbana, a qual possui carências de infraestrutura, como acesso à água potável de qualidade e sistema de canalização e tratamento de esgoto. Considerando que a população possui, predominantemente, baixo poder aquisitivo, essa situação interfere na solução imediata dos problemas apresentados.

Apesar de a cidade estar inserida em uma das maiores bacias hidrográficas do mundo, nota-se uma precariedade no fornecimento de água. A disponibilidade hídrica do lugar não garante um abastecimento adequado à população, por razões diversas que não foram mencionadas neste artigo, uma vez que não é esse o foco.

Essas forças motrizes se apresentam como elementos definidores das pressões sobre as condições do ambiente e da saúde da população, influenciados também por um crescimento em área dos setores e pelo destino dos resíduos sólidos, lançados, muitas vezes, nos córregos.

A metodologia Peir permitiu observar a relação essencial entre saúde e ambiente. Pretende-se ampliar a análise sobre a cidade, à luz da metodologia Peir, e acrescentar outras variáveis para que seja possível melhorar os instrumentos de avaliação das condições de saúde. De acordo com as diretrizes adotadas, o ambiente estudado é vulnerável e, dessa forma, as intervenções do Poder Público nas condições de vida da população exposta se tornam necessárias para restringir a escala de problemas.

\section{Referências}

ANDRADE, S. S. Põe tapioca, farinha d’água?
Gastronomia do açaí e identidade socioespacial
e cultural na Grande Belém. 2014. Tese
(Doutorado em Desenvolvimento Sustentável do 
Trópico Úmido) - Universidade Federal do Pará, Belém, 2014.

ARIZA, C. G.; ARAUJO NETO, M. D. Contribuições da geografia para avaliação de impactos ambientais em áreas urbanas, com o emprego da metodologia Pressão - Estado Impacto - Resposta (P.E.I.R.). Caminhos de Geografia, Uberlândia, v. 11, n. 35, p. 128-139. 2010. Disponível em: <https://goo.gl/aTYohe>. Acesso em: 14 out. 2016.

BARBOSA, M. J. S. (Coord.). Relatório analítico do território do Marajó. Belém: Instituto de Ciências Sociais Aplicadas, Universidade Federal do Pará; Brasília, DF: Ministério do Desenvolvimento Agrário, 2012. Disponível em: <https://goo.gl/ W51c5V>. Acesso em: 2 fev. 2015.

BAUMAN, Z. Globalização: as conseqüências humanas. Rio de Janeiro: Zahar, 1999.

BERLINGUER, G. Globalização e saúde global. Estudos Avançados, São Paulo, v. 13, n. 35, 1999. Disponível em: 〈http://bit.ly/2qj25Ob〉. Acesso em: 23 jan. 2015.

BOTTO, M. P. et al. Estudo quanti-qualitativo da precariedade das condições de saneamento ambiental em comunidades do estado do Ceará. In: CONGRESSO BRASILEIRO DE ENGENHARIA SANITÁRIA E AMBIENTAL, 23., 2005, Campo Grande. Anais... Rio de Janeiro: ABES, 2005, p. 1-9.

BRASIL. Lei nº 1.806, de 6 de janeiro de 1953. Dispõe sôbre o Plano de Valorização Econômica da Amazônia, cria a superintendência da sua execução e dá outras providências. Diário Oficial [da] República Federativa do Brasil, Brasília, DF, 7 jan. 1966a, Seção 1, p. 276.

BRASIL. Lei n ${ }^{0}$ 5.173, de 27 de outubro de 1966. Dispõe sôbre o Plano de Valorização Econômica da Amazônia; extingue a Superintendência do Plano de Valorização Econômica da Amazônia (SPVEA), cria a Superintendência do Desenvolvimento da Amazônia (SUDAM), e dá outras providências. Diário Oficial [da] República Federativa do Brasil, Brasília, DF, 31 out. 1966b. Seção 1, p. 253.

BRASIL. Ministério da Saúde. Organização Pan-Americana da Saúde. Avaliação de impacto na saúde das ações de saneamento: marco conceitual e estratégia metodológica. Brasília, DF, 2004. 116 p.

CARVALHO, C. E. et al. Indicadores de sustentabilidade fortalecendo a constituição de agroecossistemas sustentáveis em assentamentos rurais do semi-árido sergipano. Revista da Fapese, Aracaju, v. 5, n. 1, p. 79-86, 2009. Disponível em: <https://goo.gl/fgqZJe>. Acesso em: 8 ago. 2014.

CASTRO, E. (Org.). Urbanização, pluralidade e singularidades das cidades amazônicas. In: CASTRO, E. Cidades na floresta. São Paulo: Annablume, 2008. p. 8-39.

CORRÊA, R. L. Globalização e reestruturação da rede urbana: uma nota sobre as pequenas cidades. Revista TERRITÓRIO, v. 4, n. 6, p. 43-53, jan./jun. 1999. Disponível em: 〈https://goo.gl/AjvYRh>. Acesso em: 20 abr. 2016.

COSTA, S. M.; BRONDÍZIO, E. S. Inter-urban dependency among Amazonian cities: urban growth, infrastructure deficiencies, and sociodemographic networks. Redes, Santa Cruz do Sul, v. 14, n. 3, p. 211-234, 2009.

COSTA, S. M. F. et al. Pequenas cidades do estuário do Rio Amazonas: fluxo econômico, crescimento urbano e as novas velhas urbanidades da pequena cidade de Ponta de Pedras. Redes, Santa Cruz do Sul, v. 17, n. 2, p. 5674, 2012.

COSTA, S. M. F. et al. Crescimento urbano e ocupação da várzea em pequenas cidades da Amazônia: uma discussão premente. Revista Geografia, Ensino \& Pesquisa, Santa Maria, v. 20, n. 1, p. 114-129, 2016.

IBGE - INSTITUTO BRASILEIRO DE GEOGRAFIA E ESTATÍSTICA. Censo demográfico 2010: características da população e dos domicílios: resultados do universo. Rio de Janeiro: IBGE, 2010.

KRISTENSEN, P. The DPSIR framework. WORKSHOP ASSESSMENT OF THE VULNERABILITY OF WATER RESOURES TO ENVIRONMENTAL CHANGE IN AFRICA, 2004, Nairobi. Proceedings... Nairobi: National Environmental Research Institute, 2004. 
Disponível em: <https://goo.gl/4KRgiw>. Acesso em: 6 dez. 2017.

NAKAGOMI, B. Capacidade de carga e metodologia P.E.I.R: uma nova proposta metodológica de análise ambiental. 2012. Monografia (Bacharelado em Geografia) -Universidade de Brasília, Brasília, DF, 2012. Disponível em: <https://goo.gl/oxVB3e>. Acesso em: 6 dez. 2017.

NETTO, G. F. et al. Impactos socioambientais na situação de saúde da população brasileira: Estudo de indicadores relacionados ao saneamento ambiental inadequado. Tempus: Actas em Saúde Coletiva, Brasília, DF, v. 4, n. 4, p. 53-71, 2009.

OECD - ORGANIZATION FOR ECONOMIC CO-OPERATION AND DEVELOPMENT. OECD environmental indicators: development, measurement and use: reference paper. OECD, Paris, 2003. Disponível em: <https://goo.gl/ eRWQCv>. Acesso em: 6 dez. 2017.

OLIVEIRA, J. A. A cultura, as cidades e os rios na Amazônia. Ciência e Cultura, Campinas, v. 58, n. 3, p. 27-29, 2006.

OLIVEIRA, I. G. Análise de percepção ambiental de moradores de área de várzea em pequenas cidades da Amazônia: um estudo de caso. Dissertação (Mestrado em Planejamento Urbano e Regional) - Universidade do Vale do Paraíba, São José dos Campos, 2015. Disponível em: <https://goo.gl/ i2HsNm>. Acesso em: 20 jul. 2016.

OLIVEIRA, M. L. B. C.; FARIA, S. C. Aplicação do modelo FPSEEA na construção de indicadores de saúde ambiental. In: PHILIPPI JUNIOR, A.; MALHEIROS, T. F. (Org.). Indicadores de sustentabilidade e gestão ambiental. Barueri: Manole, 2012. p. 445-471.

PARÁ. Secretaria de Estado de Agricultura. Dados agropecuários: extrativismos e silvicultura. 2013. Disponível em: <http://bit.ly/2lHnKtv>. Acesso em: 10 jan. 2015 .

PHILIPPI JUNIOR, A.; MALHEIROS, T. F. (Org.). Indicadores de sustentabilidade e gestão ambiental. Barueri: Manole, 2012. 743 p.

RIBEIRO, H. Patologias do ambiente urbano: Desafios para a Geografia da Saúde. In: LAURA,
S. M. et al. (Org.) Questões territoriais na América Latina. São Paulo: CLACSO Livros, 2006. p. 277-293.

SÃO PAULO (Estado). Secretaria de Estado da Saúde de São Paulo. Coordenadoria de Controle de Doenças. Centro de Vigilância Epidemiológica. Divisão de Doenças de Transmissão Hídrica e Alimentar. Doenças relacionadas à água ou de transmissão hídrica: perguntas e respostas e dados estatísticos: informe técnico. São Paulo, 2009.

SAUNDERS, R. J. Abastecimento de água em pequenas comunidades: aspectos econômicos e políticos nos países em desenvolvimento. Rio de Janeiro: ABES: BNH; Brasília, DF: CODEFASV, 1983.

SILVA, M. E.; CÂNDIDO, G. A. A análise de indicadores de sustentabilidade na problemática de resíduos sólidos em Campina Grande-PB. Reuna, Belo Horizonte, v. 17, n. 1, p. 91-110, 2012. VEDOVETO, M. Caracterização do mercado de açaí (Euterpe oleracea Mart.) em Belém entre 2006 e 2008. Belém: Instituto do Homem e Meio Ambiente da Amazônia, 2008. Disponível em: <https://goo.gl/y4AuKe>. Acesso em: 6 dez. 2017.

\section{Agradecimentos}

Os autores agradecem à Fundação de Amparo à Pesquisa do Estado de São Paulo (Fapesp), ao Conselho Nacional de Desenvolvimento Científico e Tecnológico (CNPq) e à Coordenação de Aperfeiçoamento de Pessoal de Nível Superior (Capes), pelo apoio ao desenvolvimento desta pesquisa.

\section{Contribuição dos autores}

Lima foi responsável pela concepção do estudo. Costa e Lima realizaram a análise dos dados. Todos os autores contribuíram para a redação do artigo.

Recebido: 07/11/2017

Aprovado: 16/11/2017 